\title{
Cardiac Function and Peripheral Circulatory Adjustments in Patients with Acute Myocardial Infarction

\author{
Observations during the Early Stage of AMI
}

\author{
Yoshihiko SeIno, M.D.*
}

\section{SUMMARY}

Since little is known concerning the effect of different types of cardiac dysfunction on the peripheral circulation in acute myocardial infarction, cardiac and peripheral circulatory hemodynamics were measured simultaneously and sequentially in the Coronary Care Unit in 40 patients with acute myocardial infarction (AMI) using a Swan-Ganz catheter and venous occlusion plethysmography.

Patients were classified by clinical assessment (Killip) and into four hemodynamic subsets (HS) according to pulmonary capillary wedge pressure (PCWP) and cardiac index (CI) measures obtained by invasive central hemodynamic monitoring (Forrester): uncomplicated AMI, HS-I (PGWP $\leq 18 \mathrm{mmHg}, \mathrm{CI}>2.2 \mathrm{~L} / \mathrm{min} / \mathrm{m}^{2}$ ) 15 ; pulmonary congestion, HS-II (PCWP $>18 \mathrm{mmHg}, \mathrm{CI}>2.2 \mathrm{~L} / \mathrm{min} / \mathrm{m}^{2}$ ) 15; peripheral hypoperfusion, HS-III (PCWP $\leq 18 \mathrm{mmHg}$, CI $\leq$ $2.2 \mathrm{~L} / \mathrm{min} / \mathrm{m}^{2}$ ) 4; cardiogenic shock, HS-IV (PCWP $>18 \mathrm{mmHg}$, $\left.\mathrm{CI} \leq 2.2 \mathrm{~L} / \mathrm{min} / \mathrm{m}^{2}\right) 6$.

Measurements taken within 48 hours after the onset of AMI showed significantly lower calf blood flow $(p<0.05)$ and calf venous capacitance $(\mathrm{p}<0.01)$ and higher calf vascular resistance $(\mathrm{p}<0.05)$ in all AMI classifications compared to 10 normal subjects.

In uncomplicated AMI group (Killip I and HS-I) calf blood flow and venous capacitance were significantly reduced while calf vascular resistance remained unchanged from normal. In AMI complicated by pulmonary congestion (Killip II and HS-II), in addition to reduced calf venous capacitance, calf blood flow was further significantly reduced $(p<0.05)$ due, in part, to a rise in calf vascular resistance $(p<0.05)$. In AMI complicated by severe heart failure and shock (Killip III, VI and HS-IV), mean changes

From the First Department of Medicine, Nippon Medical School, 'okyo, Japan.

* Recipient of a Grant-in-Aid for Scientific Research from the Ministry of Education, Science and Culture, Tokyo, Japan (1980). Dr. Seino was a research fellow of the Department of Cardiology, Cedars-Sinai Medical Center from $1980^{\circ}$ to 1982.

Address for reprint: Yoshihiko Seino, M.D., Department of Medicine, Nippon Medical School, 1-1-5, Sendagi, Bunkyo-ku, Tokyo 113, Japan.

Received for publication September 28, 1982. 
in the periphery were not statistically different from those seen in patients with pulmonary congestion alone. In patients with AMI complicated by poor peripheral perfusion (HS-III), the peripheral changes did not show significant differences from those seen in uncomplicated AMI (HS-I).

Significant correlations were found between calf blood flow and PCWP ( $\mathrm{r}=-0.37, \mathrm{p}<0.05)$ and CVP $(\mathrm{r}=-0.31, \mathrm{p}<0.05)$; calf vascular resistance and PCWP $(r=+0.36, p<0.05)$ and systemic vascular resistance $(r=+0.43, \mathrm{p}<0.01)$.

Sequential daily peripheral hemodynamic changes in $14 \mathrm{H}-\mathrm{I}$ patients not requiring specific therapy showed that calf blood flow took 5 days, calf vascular resistance 3 days and calf venous capacitance 7 days to return to within normal levels.

Our results show that 1) resistance vessel constriction is greater with higher PCWP and CVP, 2) maximum constriction of capacitance vessels occurs even in the absence of forward or backward failure, and 3 ) the constriction of capacitance vessels is more prolonged than that of resistance vessels in uncomplicated AMI.

\section{Additional Indexing Words:}

Resistance vessel plethysmography

Capacitance vessel Heart failure
Venous occlusion

$\mathrm{W}^{\mathrm{n}}$

HILE chronic heart failure is known to have profound effects on peripheral hemodynamics ${ }^{1-10}$ ) there has been little study of the peripheral hemodynamic changes occurring in the early stage of acute myocardial infarction (AMI), particularly with regard to how peripheral circulatory adjustments are made in response to various types of cardiac dysfunction.

The present study was designed to examine peripheral hemodynamic responses to central hemodynamic decompensation during the early stage of AMI and also to study the sequential changes in peripheral hemodynamics.

\section{Patients And Methods}

Forty patients (31 males and 9 females, mean age of 58 ranging 38-84) with clinical, electrocardiographic and laboratory evidence of acute transmural myocardial infarction were studied in the Coronary Care Unit of Nippon Medical School within 48 hours of onset of chest pain. Any patients with a history of peripheral vascular disease or the use of cardiotonics and/or vasodilators were excluded from the study. A control group of 10 subjects matched for age and sex and without apparent cardiovascular disease underwent the same investigations in the Coronary Care Unit. 
Peripheral and cardiac hemodynamic measurements were performed simultaneously in all patients as soon as they were received in the Coronary Care Unit and in most cases, before administration of specific drug therapy other than oxygen by nasal cannula or face mask. Three patients had been given pentazosine intravenously at the onset of chest pain, 5 patients lidocaine (50-100 mg) intravenously and 4 patients furosemide $(20-40 \mathrm{mg})$ intravenously. In these 12 patients, measurements were made at least 3 hours after stopping the drugs.

Peripheral hemodynamic measurements were performed with the patient supine using a pneumatic plethysmograph applied to the calf (EDI, pneumoplethysmograph, Winsor "Vasograph ${ }^{\circledast}$ ") as described previously. 11)-15) A venous occlusion technique was used for the measurement of calf blood flow. The plethysmographic cuff was placed around the midcalf and a second cuff applied just above the knee which allowed an immediate pressure increase by sudden inflation to $30 \mathrm{mmHg}$. Calf blood flow was calculated from the rate of change in volume during venous occlusion and expressed in units of $\mathrm{ml} / 100$ $\mathrm{ml} / \mathrm{min}$. During recording, blood flow to the foot was occluded by the use of a third cuff inflated to a suprasystolic level of pressure (usually 200$250 \mathrm{mmHg}$ ) for at least $1 \mathrm{~min}$ before determination of blood flow. Calf venous capacitance was measured by an equilibration method. ${ }^{2), 3)}$ The venous occlusion cuff was suddenly inflated to $30 \mathrm{mmHg}$ and then venous pressure and limb circumference were permitted to equilibrate for more than $2 \mathrm{~min}$. Galf venous capacitance was calculated from the increments in volume expressed in units of $\mathrm{ml} / 100 \mathrm{ml}$. During measurements, the calf was elevated at the level of the heart. Calf vascular resistance was defined as the mean arterial pressure $(\mathrm{BPm})$ measured at the popliteal artery by Korotkoff's method divided by calf blood flow in units of $\mathrm{mmHg} / \mathrm{ml} / 100 \mathrm{ml} / \mathrm{min}$. BPm was calculated by using the formula: $\mathrm{BPm}=$ diastolic blood pressure $+1 / 3$ (systolic-diastolic pressure). Repeated determinations of blood flow and venous capacitance were undertaken to insure a relatively steady state. When a steady state was considered to be present, three successive measurements were made, averaged and utilized as study data. The room temperature of the Coronary Care Unit was maintained at $24 \pm 1^{\circ} \mathrm{C}$.

Measurements and recordings of pulmonary artery pressure (PA), pulmonary capillary wedge pressure (PCWP) and right atrial pressure, i.e. central venous pressure (CVP), were performed using a Swan-Ganz thermodilution catheter inserted through a brachial vein. Cardiac output $(\mathrm{CO})$ was determined by thermodilution technique using an Edward's Model 9520A Cardiac Output Computer. Blood pressure was measured using a \#19 Teflon Cannula inserted in a radial or a femoral artery or by Korotkoff's 
method at the right brachial artery. In addition, the following cardiac hemodynamic measures were calculated:

Cardiac index $(\mathrm{CI})=\frac{\mathrm{CO}}{\text { Body Surface Area }}\left(\mathrm{L} / \mathrm{min} / \mathrm{m}^{2}\right)$

Stroke volume index (SVI)

$$
=\frac{\mathrm{CO} \times 1000}{\text { Body Surface Area } \times \text { Heart Rate }}\left(\mathrm{ml} / \mathrm{beat} / \mathrm{m}^{2}\right)
$$

Stroke work index $(\mathrm{SWI})=\mathrm{SVI} \times(\mathrm{BPm}-\mathrm{PCWP}) \times 0.0136\left(\mathrm{gm} \cdot \mathrm{m} /\right.$ beat $\left./ \mathrm{m}^{2}\right)$

Total systemic peripheral resistance (TSPR)

$$
=79.9 \times \frac{(\mathrm{BPm}-\mathrm{GVP})}{\text { GI }}\left(\text { dyne } \cdot \mathrm{sec} \cdot \mathrm{cm}^{-5} / \mathrm{m}^{2}\right)
$$

The patients were divided into 4 groups by Killip classification. ${ }^{16)}$ Killip I consisted of 14 patients considered to be free of heart failure based on the absence of S III gallop+lung crepitations; Killip II consisted of 19 patients considered to be in slight or moderate heart failure; Killip III consisted of 5 patients considered to be in severe heart failure and Killip IV consisted of 2 patients considered to be in cardiogenic shock.

The patients were also separated into four hemodynamic subsets (HS) according to PCWP and CI using Forrester's classification. ${ }^{17), 28)}$ Uncomplicated (HS-I: PCWP $\leq 18 \mathrm{mmHg}, \mathrm{CI}>2.2 \mathrm{~L} / \mathrm{min} / \mathrm{m}^{2}$ ) consisted of 15 patients, pulmonary congestion (HS-II: PCWP $>18 \mathrm{mmHg}$, CI $>2.2 \mathrm{~L} / \mathrm{min} / \mathrm{m}^{2}$ ) consisted of 15 patients, peripheral hypoperfusion (HS-III: PCWP $\leq 18 \mathrm{mmHg}$, $\mathrm{CI} \leq 2.2 \mathrm{~L} / \mathrm{min} / \mathrm{m}^{2}$ ) consisted of 4 patients and cardiogenic shock (HS-IV: PGWP $>18 \mathrm{mmHg}, \mathrm{CI} \leq 2.2 \mathrm{~L} / \mathrm{min} / \mathrm{m}^{2}$ ) consisted of 6 patients.

In addition to the recording of peripheral hemodynamics in all patients on admission, sequential daily changes in peripheral hemodynamics were observed on admission and 3, 5, 7 and 10 days after the onset of AMI in 14 patients who had no or slight heart failure (7 in Killip I, 7 in Killip II) and in whom no specific therapy (cardiotonic drugs, vasodilators or other therapy influencing peripheral vessels) other than diuretics was required. In these patients hemodynamic measurements were done prior to breakfast at approximately the same time each day.

All data are expressed as the mean \pm standard deviation and statistical analyses of comparison of peripheral hemodynamics between Killip classifications and between hemodynamic subsets were carried out using onc-way analysis of variance. Linear regression calculations between peripheral and cardiac hemodynamic measurements were performed and correlation coefficients determined. Analyses of sequential daily changes in peripheral hemodynamics were done by the Student's t-test for unpaired data. 


\section{RESUlts}

\section{Killip classification}

Table I and Fig. 1 compare peripheral hemodynamic measurements among patients grouped according to their Killip classification. Killip III and IV patients were treated as a group because of the small number of cases.

Calf blood flow in all Killip groups was significantly lower than that in normal subjects. Calf venous capacitance in all Killip groups was also significantly lower than that in normal subjects. Calf vascular resistance in Killip II and Killip III-IV was significantly higher than that in normal subjects.

Table I. Relationship between Peripheral Hemodynamics and Killip Classification

\begin{tabular}{l|cccc}
\hline & Killip I & Killip II & Killip III/IV & $\begin{array}{c}\text { Normal } \\
\text { subjects }\end{array}$ \\
\hline $\mathrm{N}$ & 14 & 19 & 7 & 10 \\
$\begin{array}{l}\text { Calf blood flow } \\
\text { (ml/100 ml/min) }\end{array}$ & $1.53 \pm 0.80^{*}$ & $0.88 \pm 0.50^{* * *+}+$ & $1.08 \pm 0.45^{* *}$ & $2.39 \pm 1.12$ \\
$\begin{array}{l}\text { Calf venous capacitance } \\
\text { (ml/100 ml) }\end{array}$ & $0.45 \pm 0.24 * * *$ & $0.41 \pm 0.10^{* * *}$ & $0.36 \pm 0.26^{* * *}$ & $1.07 \pm 0.46$ \\
$\begin{array}{l}\text { Calf vascular resistance } \\
\text { (mmHg/ml/100 ml/min) }\end{array}$ & $79.98 \pm 45.09$ & $142.73 \pm 85.35^{* *+\dagger}$ & $106.50 \pm 1.61^{*}$ & $53.75 \pm 32.13$
\end{tabular}

Values are expressed as mean \pm standard deviation.

* Normal subjects vs each classification: ${ }^{*} \mathrm{p}<0.05$, ** $\mathrm{p}<0.02$, *** $\mathrm{p}<0.01$.

Killip I vs other classification: $\dagger p<0.05$.
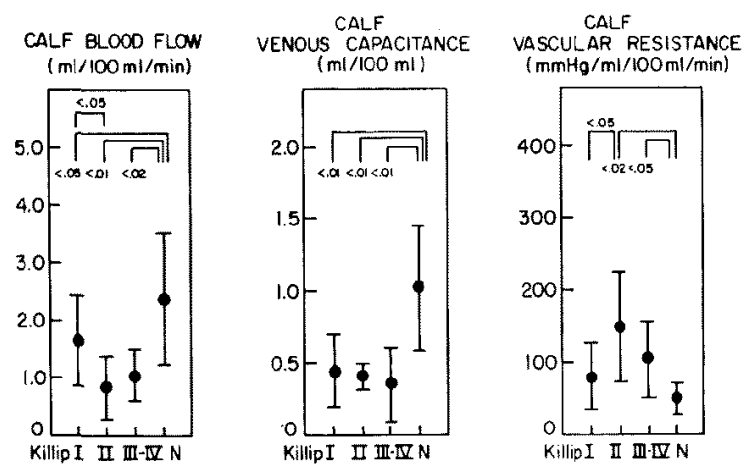

Fig. 1. This figure shows the relationship between each peripheral hemodynamic measure and the cardiac function of the patients according to their Killip classification.

Calf blood flow and venous capacitance were significantly lower in all Killip groups than in normal subjects (N). Calf vascular resistance in Killip II \& III-IV were significantly higher than in normal subjects. Killip II patients showed significantly lower calf blood flow and higher calf vascular resistance than Killip I patients. 
In making comparisons between Killip groups, Killip II showed a significantly lower calf blood flow $(\mathrm{p}<0.05)$ and higher calf vascular resistance $(p<0.05)$ than those of Killip I, but there were no significant differences in calf venous capacitance between these groups. No significant differences between Killip I and Killip III-IV were found.

Hemodynamic subsets

Table II and Fig. 2 compare peripheral hemodynamic measurements among patients grouped according to their hemodynamic subsets(HS).

Table II. Relationship between Peripheral Hemodynamics and Hemodynamic Subsets

\begin{tabular}{l|ccccc}
\hline & HS-I & HS-II & HS-III & HS-IV & $\begin{array}{c}\text { Normal } \\
\text { subjects }\end{array}$ \\
\hline $\mathrm{N}$ & 15 & 15 & 4 & 6 & 10 \\
Calf blood flow & $1.53 \pm$ & $0.97 \pm$ & $1.01 \pm$ & $0.89 \pm$ & $2.39 \pm$ \\
(ml/100 ml/min) & $0.80^{*}$ & $0.49^{*, \dagger}$ & $0.48^{*}$ & $0.16^{*} \dagger$ & 1.12 \\
Calf venous capacitance & $0.48 \pm$ & $0.40 \pm$ & $0.32 \pm$ & $0.37 \pm$ & $1.07 \pm$ \\
(ml/100 ml) & $0.24^{* * *}$ & $0.16^{* * *}$ & $0.12^{* * *}$ & $0.12^{* * *}$ & $0.46^{*}$ \\
Calf vascular resistance & $80.07 \pm$ & $141.09^{*}$ & $97.68 \pm$ & $143.80 \pm$ & $53.75 \pm$ \\
(mmHg/ml/100 ml/min) & 13.68 & $20.39^{* * *+\dagger}$ & 34.78 & $31.61^{*, \dagger}$ & 32.13
\end{tabular}

Values are expressed as mean \pm standard deviation.

* Normal subjects vs each subset: * $\mathrm{p}<0.05, * * * \mathrm{p}<0.01$.

HS-I vs other subset: ${ }^{+} \mathrm{p}<0.05$.

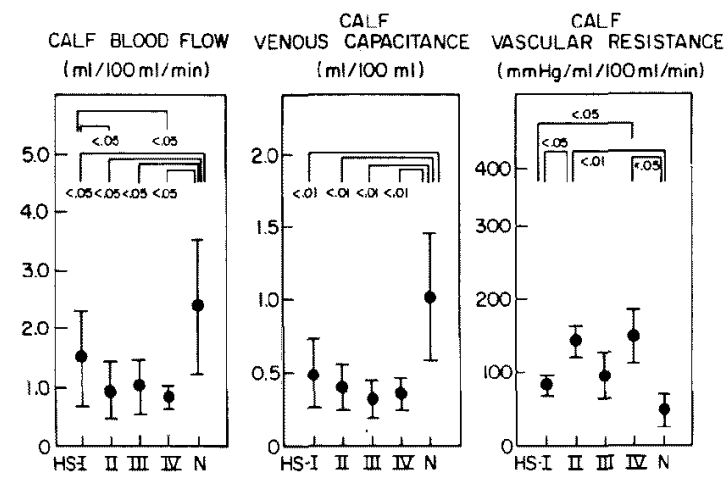

Fig. 2. This figure shows the relationship between each peripheral hemodynamic measure and the cardiac function of the patients based upon hemodynamic subsets (HS). ${ }^{23), 24}$ )

Calf blood flow and venous capacitance were significantly lower in all hemodynamic subsets (HS) than in normal subjects (N). Calf vascular resistance in HS-II and HS-IV were significantly higher than that seen in normal subjects. HS-II and HS-IV patients had significantly lower calf blood flow and higher calf vascular resistance than HS-I patients. IIS-I : hemodynamically classified uncomplicated patients. HS-II : hemodynamically classified pulmonary congestion patients. HS-III : hemodynamically classified peripheral hypoperfusion patients. HS-IV: hemodynamically classified cardiogenic shock patients. 
Calf blood flow in all hemodynamic subsets was significantly lower than that in normal subjects. Calf venous capacitance in all patients was also significantly lower than that in normal subjects. Calf vascular resistance in HS-II (pulmonary congestion) and HS-IV (cardiogenic shock) patients was significantly higher than that in normal subjects, but there were no significant differences between HS-I (uncomplicated) or HS-III (peripheral hypoperfusion) patients and normal subjects.

When comparing peripheral measurements obtained in each hemodynamic subset, HS-II (pulmonary congestion) and HS-IV (cardiogenic shock) patients had significantly lower calf blood flow $(\mathrm{p}<0.05)$ and significantly higher vascular resistance $(p<0.05)$ than those of the HS-I (uncomplicated) patients.

\section{Correlation between peripheral and central hemodynamic measurements}

Table III shows the correlation coefficients between peripheral and central hemodynamic measurements in 40 patients. There were significant correlations between calf blood flow and CVP $(r=-0.31, p<0.05)$ and PCWP ( $r=-0.37, \mathrm{p}<0.05)$, calf vascular resistance and PGWP $(r=0.36$, $\mathrm{p}<0.05)$ and TSPR $(\mathrm{r}=0.43, \mathrm{p}<0.01)$. No significant correlations were found between calf blood flow and CI, SVI or SWI. Calf venous capacitance also failed to demonstrate a significant correlation with any central hemodynamic measurement.

Sequential changes in peripheral hemodynamics

Table IV and Fig. 3 show the sequential changes of peripheral hemo-

Table III. Correlation Coefficients between Peripheral and Cardiac Hemodynamics in Acute Myocardial Infarction

\begin{tabular}{l|cccccc}
\hline & PCWP & GVP & CI & SVI & SWI & TSPR \\
\hline Calf blood flow & $\mathrm{r}=-0.37^{*}$ & $\mathrm{r}=-0.31 *$ & $\mathrm{~ns}$ & $\mathrm{~ns}$ & $\mathrm{~ns}$ & $\mathrm{~ns}$ \\
Calf venous capacitance & $\mathrm{ns}$ & $\mathrm{ns}$ & $\mathrm{ns}$ & $\mathrm{ns}$ & $\mathrm{ns}$ & $\mathrm{ns}$ \\
Calf vascular resistance & $\mathrm{r}=0.36^{*}$ & $\mathrm{~ns}$ & $\mathrm{~ns}$ & $\mathrm{~ns}$ & $\mathrm{~ns}$ & $\mathrm{r}=0.43^{* * *}$
\end{tabular}

$* \mathrm{p}<0.05, * * * \mathrm{p}<0.01$.

Table IV. Sequential Daily Changes of Peripheral Hemodynamics in AMI $(N=14)$

\begin{tabular}{l|ccccc}
\hline & Day 1 & 3 & 5 & 7 & 10 \\
\hline \multirow{2}{*}{ Calf blood flow } & $1.02 \pm$ & $1.28 \pm$ & $1.47 \pm$ & $1.71 \pm$ & $1.27 \pm$ \\
& $0.52^{*}$ & $0.77^{*}$ & 1.15 & 1.25 & 0.61 \\
Calf vascular resistance & $140.90 \pm$ & $104.52 \pm$ & $92.39 \pm$ & $81.30 \pm$ & $81.79 \pm$ \\
& $98.48^{*}$ & 74.06 & 67.59 & 50.43 & 24.50 \\
Calf venous capacitance & $0.37 \pm$ & $0.51 \pm$ & $0.49 \pm$ & $0.65 \pm$ & $0.71 \pm$ \\
& $0.14^{* * *}$ & $0.18^{* * *}$ & $0.22^{* * *}$ & 0.49 & 0.28
\end{tabular}

Normal subjects vs each value: $* \mathrm{p}<0.05$, *** $\mathrm{p}<0.01$. 


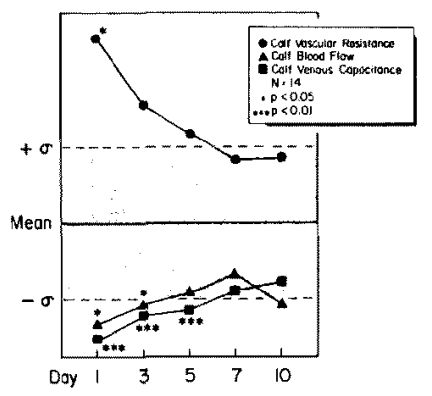

Fig. 3. Sequential daily changes of peripheral hemodynamics in 14 patients not requiring any specific therapy. The shadow zone is the normal range (mean $\pm \mathrm{SD}$ ) taken from the control group. Elevated calf vascular resistance decreased readily and returned to within the normal range on the third day. Decreased calf blood flow and calf venous capacitance increased and returned to within the normal range on the fifth and seventh days, respectively.

dynamics in 14 patients. Elevated calf vascular resistance decreased rapidly and by the third day was not significantly different from normal. Reduced calf blood flow increased day by day and was not significantly different from normal by the fifth day. Similarly, decreased calf venous capacitance increased gradually and was not significantly different from normal on the seventh day.

\section{Discussion}

The principal object of this study was to investigate the hemodynamic adjustments in peripheral circulation in relation to various states of cardiac function in the early stage of an AMI.

Killip I and hemodynamically classified uncomplicated patients

With regard to peripheral hemodynamics in AMI, Lee et al ${ }^{19)}$ found that forearm blood flow was reduced by approximately half compared with the level found subsequently during the convalescent phase of AMI. Robinson et $\mathrm{al}^{20)}$ observed reduced compliance of the dorsal hand vein in patients with AMI. Hawn et al ${ }^{21}$ reported that forearm blood flow decreased and forearm vascular resistance and venous tone increased in 14 patients with AMI who were free of chest pain, heart failure, shock and arrhythmias. Prerovsky et $\mathrm{al}^{22)}$ have reported that 16 patients with myocardial infarction developed lower values for calf blood flow and calf venous capacitance, and higher values for calf vascular resistance as compared to patients with another type of heart disease.

In the present study, there are fairly uniform findings in the peripheral 
circulation when the patient has good central hemodynamics. This does not appear to depend upon whether the patients are classified clinically (Killip) or hemodynamically (hemodynamic subsets).

Thus, in Killip Class I patients and hemodynamically classified uncomplicated patients there is a common finding of reduced calf blood flow and venous capacitance in comparison with normal control patients. There is also a common finding of unchanged calf vascular resistance which suggests that actual constriction of resistance vessels does not develop in this group.

The finding that venous capacitance was reduced in this group while calf vascular resistance was unchanged may be related to a degree of sympathoadrenal discharge occurring as a result of AMI. Mellander et $\mathrm{al}^{23}$ ) demonstrated differences in responses of resistance vessels and capacitance vessels in animal experiments. They found that the constriction of capacitance vessels in response to lumbar sympathetic nerve stimulation was rapid and greater than that of resistance vessels. Davis ${ }^{24}$ also reported similar results.

\section{Pulmonary congestion}

In myocardial infarction patients suffering from pulmonary congestion [Killip II and hemodynamically classified pulmonary congestion (HS-II) patients], there are once again common findings irrespective of whether the patients are grouped clinically or hemodynamically.

In these patients calf blood flow, which was already depressed as a result of myocardial infarction, was significantly reduced still further. This was in part due to a significantly increased calf vascular resistance compared to the uncomplicated (Killip I and HS-I) AMI group. Calf venous capacitance remained low but no further reduction occurred as a result of the presence of backward failure.

A possible reason for the lack of a significant further reduction in calf venous capacitance might be that the capacitance vessels were already constricted to a maximum level in response to the appearance of a sudden reduction in contractile myocardial mass which had occurred as a result of the myocardial infarction and before the development of heart failure.

In studies of the peripheral hemodynamics in chronic heart failure due to valvular disease, cardiomyopathies or old myocardial infarction, ${ }^{1)-10)}$ Mason et $\mathrm{al}^{1{ }^{1-3)}}$ and Zelis et $\mathrm{al}^{4)-9}$ found that in chronic heart failure forearm and calf blood flow were decreased as a result of elevated peripheral vascular resistance, and forearm and calf venous capacitance were decreased as a result of venous constriction. They postulated that resistance vessels were constricted to maintain tissue perfusion pressure and to redistribute the reduced cardiac output to more essential organs away from the extremities, while 
capacitance vessels were constricted to augment venous return to the heart.

Severe failure and shock

In myocardial infarction patients suffering from severe heart failure and cardiogenic shock (Killip III-IV and hemodynamically classified cardiogenic shock patients), the findings of reduced calf blood flow, increased calf vascular resistance and diminished calf venous capacitance were similar to those seen in patients suffering from pulmonary congestion. There were no statistically significant differences in peripheral hemodynamics between patients suffering from pulmonary congestion and those with severe failure and cardiogenic shock.

Peripheral hypoperfusion

When the peripheral hemodynamic changes observed in patients suffering from forward failure uncomplicated by backward failure (hemodynamically classified peripheral hypoperfusion patients) are considered, one sees a reduction in calf blood flow and venous capacitance. There was no significant alteration in calf vascular resistance from that seen in normal subjects suggesting that actual constriction of resistance vessels did not develop and thus adequate peripheral circulatory adjustments did not occur and as a result this subset of patients remained uncompensated.

These data also confirm that a true reduction in calf blood flow occurs in those patients who are classified as "peripheral hypoperfusion"17),18) based on invasive central hemodynamic information.

\section{Correlations between central and peripheral hemodynamics}

When correlations between cardiac and peripheral hemodynamic measurements are considered (Table III), constriction of resistance vessels correlatcd with clevated PCWP and/or CVP and increasing systemic vascular resistance, while capacitance vessels showed no such correlation.

The tendency of resistance vessels to constrict which becomes manifest with higher PCWP and/or CVP might mean that in the presence of heart failure there develops a gradual change of circulatory adjustment which serves to redistribute the cardiac output centrally away from the extremities. It might also reflect a compensatory mechanism to maintain arterial blood pressure. However, this same vasoconstriction might increase afterload excessively to impair ischemic myocardium.

\section{Sequential changes in peripheral hemodynamics}

There has been only one report by Lee et al ${ }^{19)}$ concerning this question. They observed that forearm blood flow, which was reduced at the time of admission, returned to the normal range 4 to 9 weeks later during the convalescent phase. Our results in uncomplicated AMI showed that the constriction of capacitance vessels lasts for a longer period ( 7 days) than does 
constriction of resistance vessels where changes returned to the normal range within 5 days. It has been demonstrated in animal experiments that constriction of veins in response to norepinephrine, epinephrine and sympathetic nerve stimulation was greater than constriction of arteries and that following stimulation of sympathetic nerves the constriction persisted for a longer period in venous segments compared to arterial segments. ${ }^{23), 24)}$ These findings are in agreement with our results in AMI patients.

\section{Mechanisms}

Since venous constriction was observed in patients with uncomplicated AMI and constriction of capacitance and resistance vessels in patients with AMI complicated by heart failure, augmented sympathoadrenal discharge may be a possible mechanism explaining these changes.

Toennesen et $\mathrm{al}^{25)}$ reported that although no correlation was found between plasma norepinephrine, hand blood flow and cardiac output, a statistically significant correlation existed between changes in hand blood flow and vascular resistance and changes in plasma norepinephrine in patients with AMI. Thomas et ali1 $^{11}$ reported that the plasma norepinephrine concentration was directly related to the degree of left ventricular dysfunction (New York Heart Association Class). They also found that the ratio of the preejection period to left ventricular ejection time, which is a reflection of left ventricular function, significantly increased with increasing levels of plasma norepinephrine in patients with congestive heart failure. Cohn et al ${ }^{27}$ also showed significant relationship between systemic vascular resistance and plasma levels of norepinephrine and plasma renin activity in patients with congestive heart failure. These reports support our data in that gradual vasoconstriction in peripheral resistance vessels might be due to sympathoadrenal discharge related to the severity of cardiac decompensation.

It has been demonstrated in chronic heart failure that increased vascular resistance is also related to so-called vascular stiffness i.e. an increase in vascular sodium content and an increase in tissue pressure. ${ }^{281}$,29) Hypoxemia, hypercapnea, venous pressure and local factors also may be important in changing peripheral blood flow.

Studies have shown different peripheral reflex adjustments may be provoked during experimental coronary occlusion, ${ }^{30}>$ i.e. some have shown peripheral vasoconstriction while others have shown peripheral vasodilation. The latter was interpreted as being caused by such modifications in systemic hemodynamics as the development of hypotension or a shock state. ${ }^{31}$ )

However, these experimental studies were done in innervated animal limbs, which meant excluding the role of neurohumoral regulation. In the present clinical study only significant degrees of vasoconstriction of the peri- 
pheral resistance and/or capacitance vessels were observed in patients with early stage AMI.

The fact that maximum and prolonged constriction of capacitance vessels occurred readily is interpreted as indicating a shifting of blood centrally to augment cardiac filling and increase cardiac output which results in successful compensation in hemodynamically classified uncomplicated and pulmonary congestion subsets, however it is not adequate in peripheral hypoperfusion and cardiogenic shock patient subsets.

There may be a common mechanism of vasoconstriction in AMI and chronic heart failure, but there also are important differences. Because of the sudden onset and rapid aggravation of systemic hemodynamic disturbances in AMI, some mechanisms such as the increase in vascular sodium content seen in chronic failure may not have time to develop. This however is speculative. A vicious cycle might easily be provoked in AMI when hemodynamic function is depressed to sub-optimal levels ${ }^{32)}$; thus the cardiovascular system might overcompensate such that the peripheral vascular resistance increases and the cardiac output decreases to inappropriate levels. Correspondingly, systemic venoconstriction might also be excessive, thereby resulting in a greater increase of venous return than is required relative to cardiac output on the flattened ventricular function curve characteristic of impaired contractility. Vasodilator therapy is now commonly used in the management of heart failure complicating AMI and this supports the present findings regarding the peripheral vascular pathophysiology of AMI. ${ }^{33)}$

\section{Acknowledgments}

The author wishes to express the gratitude to all staff of Coronary Care Unit, Nippon Medical School for the warm hearted assistance, to the Department of Cardiology, Cedars-Sinai Medical Center (H.J.C. Swan, M.D. and all other staff) for the continuous exchanging of the studies under fellowship, and to Eiichi Kimura, M.D. and John K. Vyden, M.D. for the critical review of the manuscript.

\section{REFERENCES}

1. Mason DT: Congestive Heart Failure, ed by Mason DT, Yorke Medical Books, New York, 1976

2. Mason DT, Braunwald E: Studies on digitalis. X. Effects of ouabain on forearm vascular resistance and venous tone in normal subjects and in patients in heart failure. J Clin Invest 43: 532,1964

3. Mason DT, Braunwald E: The effects of nitroglycerin and amyl nitrate on arteriolar and venous tone in the human forearm. Circulation 32: 755, 1965

4. Lelis R, Longhurst J, Capone RJ, Lee G, Mason DT: Peripheral circulatory control mechanisms in congestive heart failure. in Congestive Heart Failure, by Mason DT, Yorke Medical 
Books, New York, p 129, 1976

5. Zelis R: The Peripheral Circulation, ed by Zelis R, Glinic Cardiology Monographs, New York, 1975

6. Zelis R, Mason DT, Braunwald E: A comparison of the effects of vasodilator stimuli on peripheral resistance vessels in normal subjects and in patients with congestive heart failure. J Clin Invest 47: 960, 1968

7. Zelis R: The contribution of local factors to the elevated venous tone of congestive heart failure. J Clin Invest 54: 219, 1974

8. Zelis R, Nellis SH, Longhurst J, Mason DT: Abnormalities in the regional circulation accompanying congestive heart failure. Prog Cardiovasc Dis 18: 181, 1975

9. Zelis R, Longhurst J, Capone RJ, Lee G: Peripheral circulatory control mechanisms in congestive heart failure. Am J Cardiol 32: 481, 1973

10. Schweitzer P, Pivouka M, Kivanova $\mathrm{H}$ : The blood flow in the forearm in patients with cardiac failure. Zeitschrift fur die Gesamte Experimentalle Medizin 143: 126, 1967

11. Vyden JK, Nagasawa K, Graettinger W, Marcus HS, Groseth-Dittrich M, Swan HJC: The effects of transfemoral catheterization on blood flow in the extremities. Circulation 50: 741, 1974

12. Seino Y, Vyden JK, Philippart M, Rose HB, Nagasawa K: Peripheral hemodynamics in patients with Fabry's disease. Am Heart J 105: 783, 1983

13. Hyman $\mathrm{C}$, Winsor $\mathrm{T}$ : The application of the segmental plethysmograph to measurement of blood flow through the limb of human beings. Am J Cardiol 5: 667, 1960

14. Lippman HL, Winsor $\mathrm{T}$ : Medical instrumentation in peripheral vascular disease. Circulation 45: A285, 1972

15. Ogawa T, Vyden JK, Rose HB, Kanazawa M, Seino Y, Swan HJC: Peripheral circulatory changes after physical conditioning in coronary artery disease patients. $J$ Cardiac Rehab 1: 269,1981

16. Killip T, Kimball JT: Trcatment of myocardial infarction in a coronary care unit. Am J Cardiol 20: 457, 1967

17. Forrester JS, Diamond GA, Chatterjee K, Swan HJC: Medical therapy of acute myocardial infarction by application of hemodynamic subsets. New Engl J Med 295: 1356, 1976

18. Forrester JS, Diamond GA, Swan HJC: Correlative classification of clinical and hemodynamic function after acute myocardial infarction. Am J Cardiol 39: 137, 1977

19. Lee $\mathrm{G}$ : Total and peripheral blood flow in acute myocardial infarction. Br Heart J 19: 117,1957

20. Robinson BF, Collier J, Nachev $\mathrm{CH}$ : Changes in peripheral venous compliance after myocardial infarction. Circulation 44 (Suppl II): II-175, 1971

21. Hawn JA, Rhyneer GS, Bristow JD: Forearm blood flow and venous tone in acute myocardial infarction. Circulation 44 (Suppl II): II-175, 1971

22. Prerovsky I, Fabian J, Hammer J: Peripheral circulation in cardiac emergencies. Bibl Anat 11: 442, 1973

23. Mellander S: Comparative studies on the adrenergic neurohormonal control of resistance and capacitance blood vessels in the cat. Acta Physiol Scand 50 (Suppl 176): I-86, 1960

24. Davis DL: Effect of sympathetic stimulation on dog paw volume. Am J Physiol 205: 989, 1963

25. Toennesen KH, Lindskow J, Amtorp O: Hand blood flow, plasma norepinephrine and central hemodynamics in myocardial infarction. Scand J Glin Lab Invest 34: 133, 1974

26. Thomas JA, Marks BH: Plasma norepinephrine in congestive heart failure. Am J Cardiol 41: 233, 1978

27. Cohn JN, Levine B, Francis GS, Goldsmith S: Neurohumoral control mechanisms in congestive heart failure. Am Heart J 102: 509, 1981

28. Zelis R, Mason DT: Diminished forearm arteriolardilator capacity produced by mineral corticoid induced salt retention in man. Circulation 41:589, 1970 
29. Kramer RS, Mason DT, Braunwald E: Augmented sympathetic neurotransmitter activity in the peripheral vascular bed of patients with congestivc heart failure and cardiac norepinephrine depletion. Circulation 38: 629, 1968

30. Hanley HG, Costin JC, Skinner NS: Differential reflex adjustments in cutaneous and muscle vascular beds during experimental coronary artery occlusion. Am J Cardiol 27: 513, 1971

31. Hughes JG, Amsterdam EA, Mason DT, Monsour E, Zelis R: Abnormal peripheral vascular dynamics in patients with acute myocardial infarction. Clin Res 19:321, 1971

32. Mason DT: Symposium perspective. Symposium on vasodilator and inotropic therapy of heart failure. Am J Med 65: 101, 1978

33. Seino $Y$, Takano $T$, Endo $T$, Obayashi $K$, Hayakawa H, Vyden JK, Rose HB, Kimura E: Unloading effects of vasodilators on peripheral circulation and cardiac hemodynamics in patients with acute myocardial infarction. Jpn Heart J 23: 905, 1982 